\title{
Antxoaren maneiu eta kontserbazioa: biomasan eragiten duten faktoreen azterketa
}

\author{
(The use and preservation of the anchovy: analysing the factors \\ affecting their biomass)
}

\author{
Estibalitz Txurruka Alberdi*1, Ziortza Barroeta Legarreta ${ }^{1,2}$, \\ Álvaro Fanjul Miranda ${ }^{3}$ \\ ${ }^{1}$ Landare Biologia eta Ekologia saila, Zientzia eta Teknologia Fakultatea. UPV-EHU \\ ${ }^{2}$ Itsas Biologia eta Bioteknologia Esperimentalen Ikerketa Zentroa \\ (Plentziako Itsas Estazioa; PiE-UPV/EHU
}

${ }^{3}$ Ambiotek S.L.

LABURPENA: Antxoa arrantza-munduko genero pelagiko garrantzitsuenetariko bat da. Bizkaiko Golkoan, 2005 eta 2010 bitartean antxoaren arrantza debekatu egin zen aurreko urteetan izandako errekrutamendu baxuak zirela eta. Halakorik errepikatu ez dadin populazioaren egoera eta honi eragiten dioten faktoreak zeintzuk diren jakitea garrantzitsua da; hala nola tamaina handiko indibiduoen kopurua zein den, harrapariak, korronteak, parasitoak, birusak eta bakterioak, ibaien lumak, zooplanktonaren (beraren elikagaia) ugaritasuna eta komunitatearen estruktura/dibertsitatea etab. Antxoaren biomasan (eta errekrutamenduan) zuzenean eragiten duten faktore horietaz gainera, badira zeharkako eragile batzuk ere, antxoaren elikagai nagusia den zooplanktonean eragiten dutenak hain zuzen ere. Adibidez, uraren tenperatura, fitoplanktona, gazitasuna, upwellinga, etab. Eragile horiek kontuan ez hartzeak ondorioak ekarri ditzake etorkizuneko antxoaren biomasan eta, beraz, horiek aztertzea ezinbestekoa da.

HITZ GAKOAK: antxoa, zooplanktona, biomasa, eragileak edo faktoreak, energia erreserbak.

ABSTRACT: The anchovy constitutes one of the most important pelagic fish genera fisheries. Due to several years of low recruitment in the Bay of Biscay, this fishery was closed between the years 2005-2010. To avoid this situation to be repeated in the future, it is important to take into account the population status and other factors involved, such as determining the abundance of big-sized individuals, water currents, predators, parasites and microorganisms causing diseases, river plumes, the structure and diversity of zooplankton (their main food source)... etc. In addition to the previously mentioned variables acting directly on anchovy's biomass and recruitment, there are also indirect effects caused by other factors, such as those affecting zooplankton. Some examples of these factors are water temperature, phytoplankton, salinity, upwellings... Not considering all of the previously mentioned variables could cause a negative effect on the future biomass of anchovies, therefore their study is much needed.

KEYWORDS: anchovy, zooplankton, biomass, factors, energy reserves.

* Harremanetan jartzeko / Corresponding author: Estibaliz Txurruka Alberdi, Landare Biologia eta Ekologia saila, Zientzia eta Teknologia Fakultatea. Euskal Herriko Unibertsitatea (UPV/EHU). 48940 Leioa-Erandio Gunea, Bizkaia. Euskal Herria. estibalitz.txurruka@ehu.eus - https://orcid.org/0000-0001-9512-9672.

Nola aipatu / How to cite: Txurruka Alberdi, Estibalitz; Barroeta Legarreta, Ziortza; Fanjul Miranda, Álvaro (2020). «Antxoaren maneiu eta kontserbazioa: biomasan eragiten duten faktoreen azterketa»; Ekaia, ale berezia 2020, 299-320. (https://doi.org/10.1387/ekaia.21056).

Jasoa: 31 iraila, 2019; Onartua: 02 urtarrila, 2020

ISSN 0214-9001 - elSSN 2444-3255 / (c) 2020 UPV/EHU

(c) (i) (0) Obra hau Creative Commons Atribución 4.0 Internacional-en

lizentziapean dago 


\section{SARRERA}

Arrantza- sektorean mundu mailan garrantzia handiena duten espezieak espezie pelagikoak dira. Antxoa espezieen artean antxoa europarra (Engraulis encrasicolus) hirugarren espezie garrantzitsuena da, zeina Ipar Itsasotik Mediterraneora arrantzatzen baita. Zenbait urtez jarraian (2000tik aurrera) errekrutamendu kaskarra jasan ondoren, biomasaren minimo historikoetara heldu zen Bizkaiko Golkoan (1. irudia) [1]. Populazioaren kolapso horren arrazoia Ekialdeko Atlantikoko (EA) balio positiboen, udaberriko upwelling txikien eta turbulentzia handien arteko nahasketa bat izan zela proposatu da. Populazioari suspertzeko denbora emateko, antxoaren arrantza debekatu zen 2005etik 2010era [2, 3, 4]. Ordutik, biomasak gora egin du, eta Bizkaiko Golkoko populazioaren egoera hobetu da. Hala ere, biomasaren balio minimo horiek berriz ere gerta ez daitezen, antxoa populazioaren egoera biologikoa ezagutzea ezinbestekoa da.

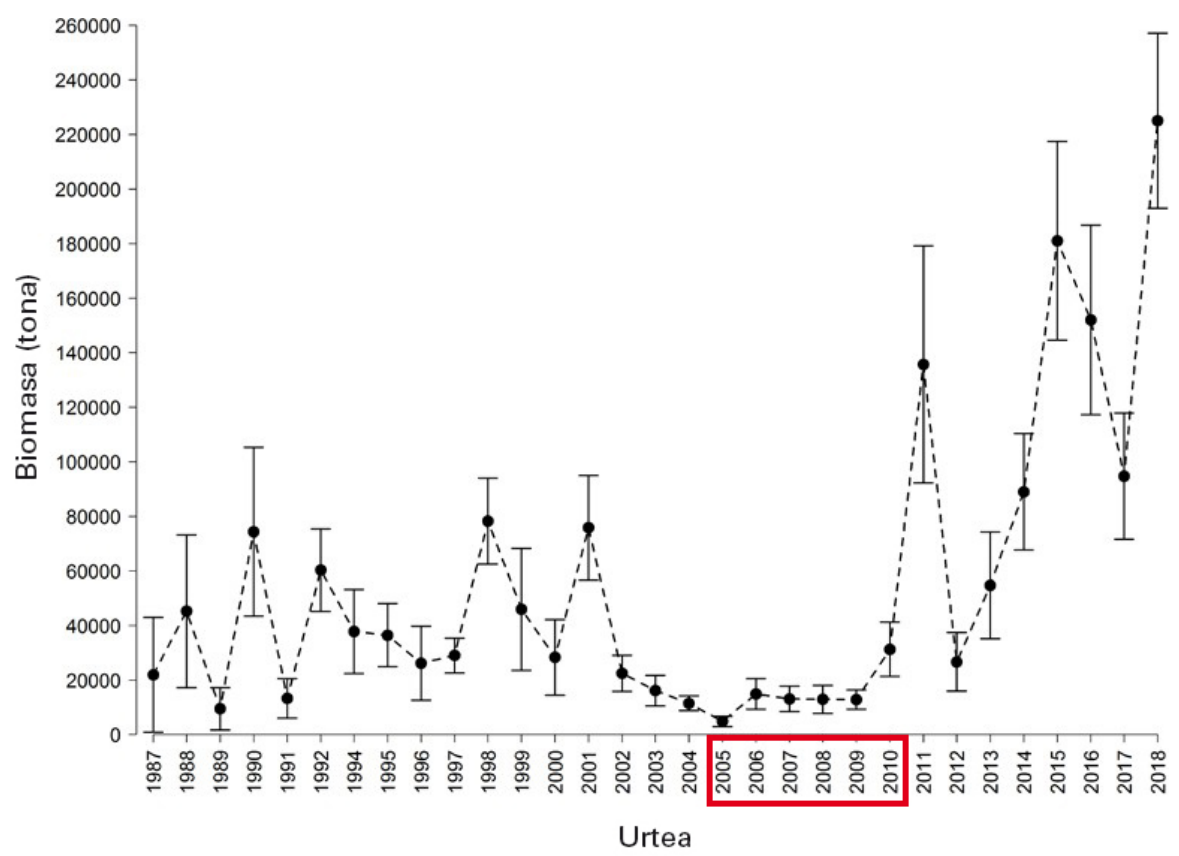

1. irudia. Bizkaiko Golkoko antxoaren biomasaren balio totalen (tonak) serie historikoa (1987-2018) (ICES 2018-tik ateratako grafiko moldatua) [5]. Gorriz, antxoaren arrantza debekatuta egon zen urte tartea.

Antxoaren populazio-dinamika nagusiki errekrutamenduaren mendekoa da, hots, ale helduen multzoari urtero gehitzen zaizkion ale berrien ko- 
puruaren mendekoa [6]. Antxoak errundako arrautza kopuruaren eta bertatik jaiotako larben kopuruaren eta helduen kopuruaren artean erlazio zuzenik ez egoteak agerian uzten du inguruneak (eragile biotiko eta abiotikoak) fase goiztiarreko heriotza-tasan eragin zuzena duela [7]. Era berean, Aldanondok [8] jakinarazi zuen urteko errekrutamenduan eragin handia izan zezaketen eragileetako bi erreklutamenduari berari loturiko hilkortasuna (arrautzen eta larba goiztiarrena) eta baita aleen neguko hilkortasuna izan zitezkeela.

Edozein animalia helduren egoera biologikoan, erreserba energetikoek berebiziko garrantzia dute. Zenbat eta erreserba energetiko gehiago izan animaliak, orduan eta egoera biologiko hobea izango du; izan ere, erreserba energetiko nahikoa ez izateak baldintza kaskarreko egoerei aurre egiteko aukerak murrizten ditu [9]. Hots, indibiduo batek oinarrizko funtzioak betetzeko adina energia badu soilik, oinarrizko funtzio horiek aldatzen dituen edozein ingurune-baldintzak indibiduo horren heriotza ekar lezake. Hori dela eta, garrantzitsua da animaliak, kasu honetan antxoak, duen erreserba energetiko kopurua jakitea, horrek beraren biziraupen probabilitatean eragingo duelako.

Era berean, energia dentsitatea positiboki erlazionatzen da lipido kantitatearekin $[10,11]$, katabolizatzen den lehen osagai biokimikoa delako [12]. Lipidoak ez bezala, proteina eta karbohidratoak espezie askotan egonkor mantentzen dira, eta energia dentsitate baxuagoa dute. Lipidoak oso aldakorrak dira indibiduo batetik bestera, baita hazkuntzan zehar, urtaro edo toki batetik bestera $[13,14,15]$. Halaber, indibiduoak duen lipido kantitatea, eskuragarri duen elikagai kopuruaren menpekoa da. Antxoak itsasoko kate trofikoaren parte dira, kate trofikoaren oinarria (planktona) eta haien harrapari diren maila trofiko altuagoko arrainak (berdela, atun gorria, hegaluzea, legatza..., esaterako) lotuz [16]. Badirudi antxoa larben ekoizpena planktonaren urteko maximoekin sinkronizatua dagoela. Eskuarki, badirudi inguruneko baldintzak optimoak izatea zein elikagai eta harraparien kopurua optimoa izatea erlazionatuta dagoela arrautzak noiz errun erabakitzeko unearekin $[17,18]$. Era berean, arrautzak erruteko leku espezifikoaren aukeraketa helduen elikadurarako baldintza optimoekin dago erlazionatuta. Hori dela eta, antxoaren hazkuntzan eta ugalketan eragiten duen edozerk kate trofikoan zeharreko energiaren transferentzian eragingo du [19]. Horrela, bada, has gaitezen antxoaren kate trofikoaren oinarrian dagoen zooplanktonean eragiten duten faktoreak aztertzen.

\section{ZOOPLANKTONEAN ERAGITEN DUTEN FAKTOREAK}

Faktore guztien artean, tenperatura da garrantzitsuena, arrautzen garapenean, elikaduran, ugalketan, arnasketan eta beste prozesu metabolikoetan 
eragiten baitu, eta, zeharka, baita elikagaien eskuragarritasunean [20]. Tenperatura latitudearekin dago erlazionatuta, latitude altuak hotzagoak baitira tropikalak baino. Hori dela eta, produkzio altuko sasoietan zooplanktonak lipido gehiago metatzen du latitude hotzetan, eta tropikoetan, aldiz, elikadura kontzentrazioa baxuagoa da [21]. Bestetik, latitudeetan gora egiteak klorofilaren eta tenperaturaren aldakortasuna handiagoa izatea dakar, baita tenperaturaren eta uraren sasoiko patroien erregulartasunarekin ere $[20,22]$. Urteko patroiak aldatzen badira (ugaritasunaren maximoak denboran aurreratu edo atzeratu direlako), harrapari-harrapakin erlazioa alda daiteke, eta, ondorioz, ur-jauzi efektuaren eraginez, kate trofiko osoan eragina izan dezake horrek.

Zooplanktonaren kopuru eta dibertsitatean eragina duten beste faktoreetako bat lehen mailako ekoizpenaren aldakortasuna da, hots, fitoplanktonaren ugaritasunaren aldakortasuna. Esaterako, ibaien itsasadarretan fitoplanktonaren bloomak (loraldiak) itsasoan baino lehenago gertatzen dira, hango egonkortasuna eta fosforo kopurua itsasoetakoa baino altuagoa delako. Bestalde, kontinente-ezpondak termoklina egonkorrago batek eta barne olatuek baldintzatzen dituzte, eta horrek zooplanktonaren tamaina handiagoa izatea ahalbidetzen du (beraz, erreserba lipidiko handiagoa dute) [23].

Argiak ere eragina du. Alde batetik, ibaietan disolbatutako substantzia humikoen ekarpenak eta sedimentuko partikula finek itsasadarretan uhertasuna handiagoa izatea eragiten dute eta, hala, argia sakonera txikiagotara helduko da (10 aldiz gutxiago) ozeanoetan baino [23]. Era berean, ibaiek ez dute soilik plataforma kontinentaletako hidrologian eragiten, urak dakarren elikagai eta sedimentu finen kopuruan ere eragiten baitute [24]. Bestetik, gizakiak eragindako eutrofizazioa ibaien uhertasunarekin dago erlazionaturik. Zenbait ikerketatan ibai mesotrofikoago batek sortutako lumak elikagai gehiago egotea ahalbidetzen duela ikusi da eta, ondorioz, fitoplanktonaren biomasa altuagoa izatea [19], eta zooplanktonaren konposizioa aldatzea [25, 26]. Era berean, Fontúrbe eta bestek [27] ikusi zuten, ezen, eutrofizazio gradu handiagoek fitoplankton komunitatea sinplifikatzen dutela, eta hala espezie baten edo gutxi batzuen nagusigoa eragiten.

Argiaren kantitateak ez ezik, iraupenak ere (fotoperiodoak) [28] zeharka eragiten dio zooplanktonari. Udaberriak aurrera egiten duen heinean, egunak luzatuz doaz eta, beraz, fitoplanktonak argi ordu gehiago du. Argi ordu kopuru horren igoeraren eta itsasoko ur zutabearen goiko geruzan dagoen elikagai kopuruaren ondorioz, fitoplanktonaren udaberriko blooma gertatzen da. Era berean, elikagai kopuruak gora egitean, zooplanktonaren biomasa ere handitzen hasten da.

Zenbait fitoplankton espezieren ugaritzeak, esate baterako urdin-berdexkenak (blue-green) edo Aphanizomenon flos-aquaren eta Anabaenaren filamentuek, zooplanktonaren ugaritasunean edo garapenean eragin deza- 
kete. Semenova eta Aleksandrov-ek [29] ikusi moduan, urdin-berdexkek dituzten toxinek eta A. flos-aquaren eta Anabaenaren filamentuek Daphnia galeataren arnas aparatua trabatzen dute, eta horren garapena murrizten uda sasoian. Era berean, urdin-berdexken balio nutrizionala diatomeoena baino txikiagoa denez, gantz azido poliase gutxiago izanik, horrek Daphniaren ugaritasuna eta tamaina txikiagoa izatea dakar. Era berean, fitoplanktonaren bat-bateko ugaritzeak zooplanktonak lehen mailako produkzioaren ugaritze hori kontrolatzea galarazten du. Fitoplankton ez-kontsumitu hori sedimentatu egiten da hil ondoren. Sedimentazio masibo horrek plataforma kontinentaleko zoruan hipoxia sorraraz dezake, eta baita deskonposizio anaerobiko horretan sortutako zenbait aerosol kutsakorren askapena ere, hala nola hidrogeno sulfuroarena eta berotegi efektua sortzen duen metanoarena [30].

Ur zutabeko beheko geruzen, zeinak hotzagoak eta elikagaitan aberatsagoak baitira, azaleratzeari upwelling esaten zaio. Azaleratze horiek zirkulazio termohalinoaren ondorioz gertatzen dira, hots, poloetan hondoratzen diren ur masak itsas hondoan zehar garraiatzen dira eta ezponda kontinental batekin topo egitean azaleratu egiten dira, eta hala upwellingak sortzen dituzte [31]. Haizeak ere azaleratze txikiak eragin ditzake. Haizeak, ur zutabearen goi geruza mugitzen du. Mugimendu horrek nahaste txikiak sortzen ditu, itsasertzeko ur zutabea homogeneo mantentzen laguntzen duten upwelling txikiak sortuz [32]. Halaber, itsaso barneko tenperaturaren eraginez sortutako ur zutabearen estratifikazioa udazkenera arte mantentzen da, sasoi horretan eguzkiaren indarra txikitzen hasten da eta haizea gogor jotzen hasten da, ur zutabea nahastea ahalbidetuz. Haizeak ur-azala itsas barnera garraiatzen du Ekmanen garraioaren ondorioz eta, horrela, ur zutabeko beheko geruzak azaleratu eta nahastea sortzen da [30]. Hala, haizearen norabidea faboragarria denean eta haren iraupena nahikoa handia, upwelling horien intentsitatea handiagoa izango da, eta luzaroan mantenduko dira eta, ondorioz, goi geruzak mantenugaitan aberastu eta zooplanktona ugarituko da.

Gazitasuna ere aipatu behar da, zooplanktonaren komunitatea eta ugaritasuna baldintzatzen baititu. Izan ere, espezie baten agerpena edo desagerpena eragin dezake, espezie bakoitzak gazitasunarekiko tolerantzia maila desberdina baitu [33].

Zooplanktonaren biomasa ere haren harraparien menpe dago. Zooplanktona arrain edo organismo gelatinakarek kontsumitzen dute. Beraz, harrapari horien ugaritzeak zooplanktonaren ugaritasuna murrizten du [34]. Bizkaiko Golkoan 2006ko udaberrian zegoen kopepodo proportzio baxua, esaterako, organismo gelatinakaren (knidario eta sifonoforoak batik bat) proportzio altuarekin erlazionaturik dago [35].

Gizakiak sortutako aerosolek eta Saharatik datorren hautsak gune oligotrofikoetako bakterioen (ziklopodo eta apendikularien elikagaiak [32]) 
ekoizpenean laguntzen dutela ikusi da. Bi aerosol horiek fosforoa dakarte, besteak beste, zeina mantenugai mugatzailea den itsasoetan. Gizakiak sortutako aerosol antropologikoek kutsadura atmosferikoa eragiten dute, zeinak Saharako hautsak baino askoz ere (1,4 aldiz gehiago ere bai) eragin handiago duen. Horrela, kutsadura atmosferiko horrek Saharatik datorren hautsaren fosforo kontzentrazioa handitzea eragiten du. Beraz, kutsaduratik gertu dauden guneek fosforoaren ekarpen handiagoa izango dute hain kutsatuak ez dauden guneekin alderatuz [36]. Horrek, aurretik aipatu den moduan, bakterioetan eragina izateaz gainera, ziklopodo eta apendikularioetan ere badu eragina.

Azkenik, gizakiaren beste aktibitate batzuek, esaterako, zentral hidroelektrikoek, laborantzako irrigazio eta ongarritzeak, eta abarrek tenperatura, erosioa eta mantenugaien ekarpena aldatzen dituzte, ibai edo erreketan, lakuetan eta estuarioetan sarri gertatzen diren konposizio biokimiko eta biologikoen aldaketen eragileak izanik [21].

\section{KATE TROFIKOKO HURRENGO MAILA, ARRAINAK}

Behin kate trofikoaren oinarrian zer faktorek eragiten duten ikusirik, katean maila bat gorago dauden organismoei (besteak beste, antxoei) zerk eragiten dien aztertuko dugu. Kontuan hartuz antxoaren garapenaren faseetan eragile desberdinak daudela, fase goiztiarreko arrautza, larba eta gazteetan eragiten dutenak aztertuko dira lehenik, eta, ondoren, heldu fasean eragiten dutenak.

\subsection{Fase goiztiarra}

Arestian aipatu bezala, antxoaren biomasan gehien eragiten duena heldu aurreko faseetako heriotza tasa da. Alegia, arrautzen, larben eta gazteen heriotza tasak eragin zuzena du errekrutamenduan. Zenbat eta arrautza gehiagok eklosionatu, orduan eta larba eta gazte gehiagok izango dute heldu fasera iristeko aukera.

Harrapariek eragin zuzena izango dute bai arrautzen heriotza tasaren zein larben kopuruan gainean [37, 38, 39, 40, 41, 42, 43, 44, 45, 46]. Izan ere, zenbat eta harrapari gehiago izan, orduan eta arrautza gutxiagok eklosionatuko dute eta larba gutxiago helduko dira gaztarora eta, azkenik, heldu fasera. Horien ingestioa urtearen eta harrapari potentzialen espezieen araberakoa da. Era berean, tokian tokiko ingestio-tasa aldatzen bada ere, ingestio-tasa handienak antxoaren errute guneak direla ikusi da [47]. Errute gune nagusia Bizkaiko Golkoan, ibai nagusien lumen eraginpeko gunea (Garona eta Aturri) eta Capbreton dira [18]. Harrapari potentzialak antxoarekin nitxoa konpartitzen duten zenbait arrain espezieren larbak, gazteak 
edo helduak dira, hala nola sardina (Sardina pilchardus) (antxoen arrautzen harrapari nagusia, batez ere $130 \mathrm{~mm}$-tik gorakoak; esaterako, Hegoafrikan, sardinek antxoen arrautzen \% 56 jaten dutela ikusi da; Bizkaiko Golkoan, arrautzen heriotzen \% 6-20ren eragile da sardina), ijito-sardina (Sprattus sprattus), Atlantikoko berdela (Scomber scombrus), txitxarroa (Trachurus trachurus) eta boga (Boops boops). Baina antxoen arrautzen heriotza tasan arrainek (\% 31-43) adinako garrantzia du makrozooplanktonak [48]. Hala, organismo gelatinakarek Chesapeake Badiako Anchoa mitchilii-ren arrautza eta larben \% 20 baino heriotza tasa handiagoa eragiten dutela ikusi da [49]. Harrapari horien artean, antxoak eurak ere sartu behar ditugu. Izan ere, gainerako espezie pelagikoen elikadura iturria ugalketa sasoian antxoa arrautzak izan daitezkeen moduan, antxoetan kanibalismoa gertatzen dela ikusi da, antxoek euren arrautzak jaten baitituzte. Hala ere, kanibalismoak eragindako heriotza tasa ez da oso handia (\% 1 dela jo da) [47].

Elikadurak bi modutan eragiten du antxoaren fase goiztiarrean. Alde batetik, antxoak larben eta gazteen aho tamainaren ondorioz (sardinek baino aho handiagoa dute) tamaina handiagoko harrapariez elika daitezke eta, ondorioz, hazkuntzara bideratu dezaketen energia kopurua handiagoa izango da (zenbat eta gehiago eta bizkorrago hazi, orduan eta aukera handiagoa izango dute euren harrapariengandik ihes egiteko) [21]. Eta, bestetik, fase goiztiarren harraparien elikadura dugu. Horrela, harrapari horien dietaren lehentasunek, predazioaren arrakastak, energia kontsumoaren eskakizunak eta bestek baldintzatzen dute harraparien presioa [47].

Gazte kopuruan eragiten duen beste faktore bat negua izango da, gazte fasetik heldu fasera errekrutatuko diren indibiduo kopuruan eragiten baitu. Ekoizpen primario eta sekundarioa nabarmenki murrizten dira sasoi hone$\tan$ fotoperiodoaren eta tenperaturaren jaitsiera dela eta [17]. Tenperaturak kontsumo tasaren erregulazioan paper garrantzitsua jokatzen duenez, espezie askok elikadura partzialki edo guztiz murrizten dute. Era berean, metabolismoa murrizten bada ere, une batetik aurrera kontsumoak ahorakina gainditzen du, eta hala energia defizita sortzen da. Hori guztia dela eta, negu hotzek gazteen errekrutamendua gutxitu dezakete (indibiduo txikienek energia erreserba gutxiago izaten dute, eta horiek bizkorrago kontsumitzen dituzte tasa metabolikoaren alometria dela eta), eta negu epelek, aldiz, positiboki eragin dezakete errekrutamenduan [50].

Urte batetik bestera 2+ ( 2 urtekoak eta nagusiagoak) adineko antxoa populazioa egonkor mantentzen da, baina 1 urteko antxoa populazioa askoz ere aldakorragoa da; izan ere, populazio totalera gehitzen den antxoa gazte kopuruaren araberakoa da [51]. Honela, antxoaren biomasa totala, antxoa gazte horien menpekoa da erabat, eta beraz, oso garrantzitsua da urtez urte nola aldatzen den jakitea. 
Estibalitz Txurruka Alberdi, Ziortza Barroeta Legarreta, Álvaro Fanjul Miranda

\subsection{Heldu fasea}

Behin heldu fasera iritsita, elikadurak izango du eraginik handiena; izan ere, zooplanktonaren eskuragarritasuna zuzenki lotua dago arrain pelagiko txikien biomasarekin. Hala, zooplanktonaren biomasan eragiten duen faktore orok (aurreko atalean aipatutakoak) zein haren komunitate estrukturan/osaeran eragiten dutenek antxoaren biomasan izango dute eragina. Aipatu beharra dago, Bizkaiko Golkoan arrain pelagiko txikien dietan gainjarpen nabarmena dagoela $(0,6)$. Beraz, elikagaiak lortzeko lehia egon daiteke sasoi eta toki batzuetan. Antxoek kopepodo kalanoideetan oinarrituriko dieta dute, batez ere Centropages eta Temora generoko espezieetan aberatsa, baina harrapakin handiagoak diren eufasiazeoak eta dekapodoak ere gehitu ditzakete edozein toki edo sasoitan, sardinek edo ijito-sardinek ez bezala [52]. Oro har, horren ugariak ez diren harrapakin handiagoak garrantzitsuagoak izaten dira energia ekarpenean [53]. Hala eta guztiz, arrain espezie oro ingurune baldintza desberdinen aurrean bere portaera aldatzeko gai da eta, beraz, elikagaien kantitatean eta kalitatean egongo da energia nahikoa lortzeko gakoa [52].

Behar baino energia gutxiago eskuratzen bada, horrek kontrako baldintzei aurre egiteko metatu dezaketen energia kopuruan izango du eragina. Alegia, eskuratzen den energia kopurua baxuagoa denean egoera biologikoa okerragoa da, eta hilkortasun naturalaren tasa handitu egiten da [54] (negu hasieran egoera biologiko bereziki baxua eta ugalketa esfortzu altuak izateak helduen heriotza tasa handitzea eragin dezake). Berriki egindako ikerketa batean, egoera biologiko baxuak tamaina handiagoetan eragin handiagoa duela ikusi da eta, hortaz, tamaina handiko indibiduoen hilkortasuna ugaritu egiten da [55].

Parasito, birus eta bakterioek indibiduo batean izan dezaketen eragina handiagoa izango da horren egoera biologikoa kaskarra denean. Ugalketa/ mantentze energien arteko erlazioan aldaketa batek immunitate kostu bat ekar dezake eta, ondorioz, indibiduoak gaixotasunekiko sentikorragoak izatea [56]. Baina, Saraux eta besteren [57] ikerketek, sardinentzat bereziki arriskutsuak izan daitezkeen patogeno horiek aztertzean [58], ez zuten makroparasitoen arrastorik aurkitu; soilik arrainen $\% 77 \mathrm{n}$, mikroparasitoak. Mikroparasito horiek hepatikoak ziren eta, horien efektua oro har ezezaguna izan arren, ez zuten inolako kalterik detektatu ez mintz ez eta ostalariaren egoeran ere. Ondorioz, ikerketek iradokitzen dute oso baxua dela halako patogenoek sardinen populazioan aldaketak sortzeko gako garrantzitsua izatearen probabilitatea. Bestalde, azken urteetan, antxoak anisakis nematodoz beteta agertu izan dira Bizkaiko Golkoan. Zenbait nematodo eta tramatodoren infekzio maila antxoaren tamainaren araberakoa dela ikusi da: parasito batzuk (Aphanurus stossichi edo Hysterothylacium aduncum, adibidez) heldugabeetan edo ugalketarako prestatzen ari direnetan ugariagoak dira. Hala ere, ez dirudi gonaden garapenean eraginik dute- 
nik. Horiek horrela, azken urteetan Mediterraneoan egindako ikerketei begiratuta $[59,60,61,62,63]$, anisakisaren infekzio prebalentzia eta maila, tokiaren araberakoa dela ematen du, bitarteko eta bukaerako ostalariaren menpekoak baitira [62, 64]. Hala ere, parasitismoaren, antxoaren egoeraren eta ugalketaren artean erlaziorik egon daitekeen jakitea oso zaila da, ugalketa sasoiak eragiten dituen aldaketak oso handiak direlako eta zaila delako horren eragina isolatzea aurreko parametroen arteko kausa-efektua argitzeko [64].

Populazioaren biziraupenerako, garrantzitsuenak indibiduo handienak direla egiaztatu da zenbait urtean zehar, gazteak direnean bizirik irauteko probabilitate handiagoa dutelako (tamaina txikiagokoek baino bizkorrago egin baitezakete igeri eta harrapari gutxiago dituztelako) [65]. Gainera, ugalketa sasoian, indibiduo handi horiek erruten dituzten arrautzek, handiagoak izateaz gainera, bitelo gehiago dute (larben elikagaia), eta arrautza gehiago jartzen dituzte eta ekoizpen denbora luzeagoa dute [66, 67, 68, 69]. Arrautza handiek, txikiek baino bolumen unitateko energia kopuru txikiagoa izan arren, termino absolutuetan kopuru handiagoa dute. Beraz, $30 \mathrm{~kg}$-ko Atlantikoko bakailao (Gadus morhua) eme batek 2 kg-ko 28 emek baino arrautza gehiago sortzeaz gainera, arrautzaren bolumena eta energia totala emearen tamainarekin handitzen da. Honela, $30 \mathrm{~kg}-\mathrm{ko}$ emeak 2 kg-ko 28 emek sortzen duten arrautza sorta baino 37 aldiz energia gehiago duen arrautza sorta ekoizten du [70]. Hori dela eta, zenbait espezie pelagikorentzat, biomasa (indibiduo kopurua) handitu bada ere, populazioaren bataz besteko tamaina txikitzen bada, horrek datozen urteetan egongo den biomasan eragingo du, ingurumen baldintzak onuragarriak izan arren [69]. Badira ebidentziak erakusten dutenak ustiatutako zenbait populaziotako indibiduo handienak desagerraraztean populazio horren ugalkortasun potentziala gutxitu dela [66].

Gainera, tamaina handiko indibiduoen desagertzeak indibiduo txikiak heldutasun sexuala lehenago lortzea eragiten du. Energia erreserbak baxuak izan arren, indibiduoek beren ugalketa-inbertsioa mantendu edo handitzen badute, ugaritasuna eta errekrutamendua kopuru handitan manten daitezke sasoi batez. Baina aipatutako aldaketek kostu bat izan dezakete, eta indibiduo handienen desagertzea eragin. Halaber, negu epelagoek zooplanktonaren energia kantitatea murriztea eragingo dute. Horrela, antxoak eskuratzen duen energiaren murriztapen horrek indibiduoak muskuluaren aktibitatera bideratuko duen energia gutxituko du. Hala, haren igeriketa efizientzia murriztuko da, besterik ezean; antxoa gazteak (baita helduak ere) gosez hil daitezke behar adina harrapakin ez aurkitzeagatik, batik bat negu bukaeran [34, 35, 57]. Era berean, indibiduo ahulenak harraparien harrapakin izango dira [71]. Nahiz eta atunaren dietaren $\% 80$ sardina eta antxoa izan, haren eragina arbuiagarria dela jo da, populazioaren $\% 2$ inguru soilik kontsumitzen duelako [72]. Halaber, izurdeek duten eragina oraindik txikiagoa 
da (\% 1 baino txikiagoa). Beraz, harrapari naturalen eragina helduetan oso txikia dela esan daiteke, baina zer gertatzen da harrapari ez-naturalak garen gizakiarekin (arrantza)?

Arrantzak, populazioan aldaketa sortu edo aldaketa handitu dezake, hain zuzen ere, populazioan gero eta indibiduo txikiagoak, gazteagoak eta heldutasun sexualera goizago heltzen direnak ugarituz [73, 74, 75, 76]. Azken 25 urteetan, sardinaren eta antxoaren harrapatze tasak (lehorreratze/populazioaren biomasa) oso baxuak izan dira (\% 13 inguru antxoaren kasuan, eta \% 10 inguru sardinarenean), baina batezbestekoak asko aldatu dira balio horietatik. Espezie pelagikoentzat, ustiapen ratio optimoa 0,4 da [77], zeina soilik sardinaren kasuan gainditu baitzen 1997an. Baina hori sardinaren biomasaren beherakada gertatu baino lehenago izan zenez, inpaktua oso txikia izan dela ondoriozta daiteke. Gainera, 2010etik aurrera sardinen arrantza ratioa oso baxua izan den arren (\% 1 edo baxuagoa), ez da haren biomasaren berreskuratzerik ikusi [57]. Hortaz, ezin da esan arrantzak sortzen duela errekrutamenduaren jaitsiera, baina populazioaren biomasan eragin zuzena dauka, indibiduo helduak ugalduko diren edota ugaltzen ari diren populaziotik kentzen baitira.

\section{ALDAKETA KLIMATIKOAK ANTXOAREN BIOMASAN IZAN DEZAKEEN ERAGINA}

Aipatu beharra dago klima aldaketaren ondorioz planetako tenperaturaren igoera aurreikusten dela eta, ondorioz, itsasoak gero eta beroagoak izango direla. Berotze horrek eragin zuzena du animalien metabolismo basalean. Tenperatura igotzen den heinean, metabolismoa bizkortu egiten da. Beraz, tenperatura altuagoetan, animaliaren gastu metabolikoa eta energia erreserben gastua handiagoak izango dira. Horrela, indibiduo txikienek hazkuntzarako eta helduek ugalketarako bideratuko duten energia txikiagoa izango da, eta hala etorkizuneko biomasan eragina izango dute. Era berean, tenperatura igotzen den heinean, zenbait espezietan indibiduoen tamaina txikitu egingo dela aurreikusi da. Ondorioz, itsasoko tenperatura $1,5^{\circ} \mathrm{C}$ igotzen bada, arrainen luzera $\% 15$ txikituko da Mediterraneoan. Tamainaren halako txikitzeak, Atlantikoko berdelaren ugalkortasun gaitasunaren \% 50ko murriztea eragingo du, adibidez. Beraz, posible da ozeano epelagoek arrain gutxiago eta ugalkortasun errendimendu baxuagoa izatea [70].

Aldaketa klimatikoak haizearen norabidean eta indarrean ere aldaketak ekarriko ditu, bai eta zooplanktonean eta antxoaren arrautza eta larben banaketan ere. Izan ere, haizearen indarraren igoerak, esaterako, ur zutabearen nahaste handiagoa eragingo du, eta argiarengatik mugatua izango da ekoizpen primarioa (fitoplankton ugaritasuna). Horrek larben bizirau- 
penean eragin dezake, nahasketa handiak sortutako ekoizpen primarioaren murriztearen ondorioz. Bestetik, Ekmanen garraioaren ondorioz itsasora garraiatuak izango diren arrautza eta gazte kopurua ere handiagoa izango da, eta horrek heriotza tasa handituko du [78, 79, 80, 81]. Era berean, haizearen norabideak eragin zuzena duela jo da zenbait lanetan [82, 83, 84]: haizearen norabide egokiak (ipar-ekialdeko haizeak) arrautza eta larbak haientzat faboragarriak diren inguruneetara bideratzen ditu [85], baina ekaitz bortitzek edo bestelako norabideko haizeek arrautza edo larben hilkortasunean kontrako eragina izan dezakete [86]. Halaber, urtaroaren araberako haizeek plataformako ezpondaren zati handi bat estal dezake ur gezazko geruza batez [87].

Aipatutako tenperaturaren eta haizearen erregimen aldaketek upwellingak handitu ditzakete. Hasiera batean upwellingen handitzeak onuragarria dela dirudien arren, ekoizpen primarioa handitzen baitu, igoera hori masiboa izan daiteke. Upwelling handiago batek indibiduoak bertan mantentzeko esfortzu handiagoa eskatzen du. Modu berean, ez hain mugikorrak diren organismo zooplanktiboroak (marmokak, esaterako) goseak arrain arrautzak kontsumitzen hasiko diren masa kritiko batera hel daitezke. Era berean, marmokak aldaketa horiek sor ditzaketen hipoxiei aurre egiteko gaitasuna dute, eta, hala, arrainen gaineko presioa handitu egingo da [88].

Aldaketa klimatikoaren eraginez, Pazifikoan gertatzen den El Niño [89], EA edota North Atlantic Oscilation (NAO) moduko fenomeno meteorologikoen intentsitatea eta gertatze aldiak (haizearen norabide, intentsitate eta luzapenean eragina duena) aldatu egingo dira [1,90,91], eta horrek eragina izango du zooplanktonean eta, ondorioz, kate trofiko osoan. Esaterako, Haro-Garay eta Huato Soberanis-ek 2008an [25] iradoki zuten zooplanktoneko zenbait espezie dominanteren eskasia (hala nola Neocalanus plumchrus eta Euphasia pacifica), Fraser ibaiaren emari urria eta Georgiako itsasarteko (Kanada) fitoplanktonaren bloom goiztiarra El Niñoren ondorio direla.

Ibaien lumetan itsas hondoa etengabe mugitzeak eta lurreko mantenugaien itsasoratzeak itsasoko beste gune batzuetan baino kopepodo gehiago egotea ahalbidetzen du [18, 92, 93, 94, 95]. Ibaien luma horien tamaina ibaien fluxuaren araberakoak dira. Klima-aldaketak ziurgabetasuna sortzen du ibaien fluxuen urtez urteko aldaketetan; aldakortasun handiagoko sasoiak sortzen ditu, eta fluxuaren maximo eta minimo zorrotzagoak [96]. Alde batetik, ur fluxu maximo handiagoek (euriteek eta elurraren urtzeak sortutakoa) itsasoratuko diren mantenugaien kopurua eta uhertasuna handiegiak izatea eragin dezake, eta, hala, itsasadarreko hidrologia eta gazitasuna aldatu eta, beraz, gune horretako komunitatean aldaketak sortu [87]. Bestetik, minimo handiagoek errekak lehorraraz ditzakete, mantenugaien emaria desagertarazi eta, beraz, kate trofikoan eragin. Aldi berean, ibai edota erreken emariaren aldaketek espezie anadromoetan, hala nola ain- 
gira edo izokina, edo antxoan eta itsasoko beste espezie batzuetan eragingo dute, euren larbak ibai edo erreken estuarioetan elikatzen baitira.

\section{ONDORIOAK}

Arrantza sektorerako garrantzitsuak diren espezieen kudeaketa eta kontserbaziorako, beharrezkoa da haien biomasan zuzenean eragiten duten eragileak kontuan izatea (fase goiztiarrean zein heldu fasean eragiten dutenak). Dena den, zeharka eragiten dutenak ere aintzat hartu behar dira, esaterako zooplanktonari eragiten dion tenperatura. Klima aldaketaren ondorio garrantzitsuena tenperaturaren igoera izanik, kate trofikoaren oinarrian eragin zuzena izango du eta, ondorioz, ur-jauziaren efektuaren bidez, kate trofiko osoan. Artikulu honetan aipatutako eragileen ikerketa sakonagoak handituko du haien arteko interakzioez dugun ezaguera. Horrela, klima aldaketak sor ditzakeen etorkizuneko mehatxuei aurre egiteko gaitasuna handitu dezakegu, eta sor daitekeen biomasa galera ekiditen saia gaitezke.

\section{BIBLIOGRAFIA}

[1] BORJA A., FONTÁN A., SÁENZ J. eta VALENCIA V. 2008. «Climate, oceanography, and recruitment: the case of the Bay of Biscay anchovy (Engraulis encrasicolus)». Fisheries Oceanography, 17 (6), 477-49.

[2] COTANO U., IRIGOIEN X., ETXEBESTE E., ÁLVAREZ P., ZARAUTZ L., MADER J. eta FERRER L. 2008. «Distribution, growth and survival of anchovy larvae (Engraulis encrasicolus L.) in relation to hydrodynamic and trophic environment in the Bay of Biscay». Journal of Plankton Research, 30 (4), 467-481.

[3] ALDANONDO N., COTANO U., GOIKOETXEA N., BOYRA G., IBAIBARRIAGA L. eta IRIGOIEN X. 2016. «Interannual differences in growth and hatch-date distributions of early juvenile European anchovy in the Bay of Biscay: implications for recruitment». Fisheries Oceanography, 25 (2), 147-163.

[4] DIAZ E., TXURRUKA J.M. eta VILLATE F. 2008. «Biochemical composition and condition in anchovy larvae Engraulis encrasicolus during growth». Marine Ecology Progress Series, 361, 227-238.

[5] ICES. 2018 Report of the Working Group on Shouthern Horse Mackerel, Anchovy and Sardine (WGMHSA). 26-30 June 2018, Lisbon, Portugal. ICES CM 2018/ACOM:17.

[6] BOYRA G., MARTINEZ U., COTANO U., SANTOS M., IRIGOIEN X. eta URIARTE A. 2013. «Acoustic surveys for juvenile anchovy in the Bay of Biscay: abundance estimate as an indicator of the next year's recruitment 
and spatial distribution patterns». ICES Journal of Marine Science, 70 (7), 1354-1368.

[7] BAALI A., BOURASSI H., FALAH S., ABDERRAZIK W., EL QORAYCHY I., AMENZOUI K. eta YAHYAOUI A. 2018. «Study of reproduction of anchovy Engraulis encrasicolus (Actionpterygii, Engraulidae) in the central area of the Moroccan Atlantic coast». Journal of Materials an Environmental Sciences, 8 (12), 4467-4474.

[8] ALDANONDO N. 2010. "Young-of-the-year European anchovy in the Bay of Biscay. Study of recruitment determining processes based on otolith microstructure analysis». UPV/EHU, $181 \mathrm{pp}$.

[9] BAALI A., BOURASSI H., FALAH S., ABDERRAZIK W., EL QORAYCHY I., AMENZONI K. eta YAHYAOUI A. 2017. «Study of reproduction of anchovy Engraulis encrasicolus (Actinopterygii, Engraulidae) in the central area of the Moroccan Atlantic coast». Journal of Materials and Environmental Sciences, 8 (12), 4467-4474.

[10] RAND P.S., LANTRY B.F., O' GORMAN R., OWENS R.W. eta STEWART D.J. 1994. «Energy Density and Size of Pelagic Prey Fishes in Lake Ontario, 1978-1990: implications for Salmonine energetics». Transactions of the American Fishery Society, 123, 519-534.

[11] VAN PELT T.I., PIATT J.F., LANCE B.K. eta ROBY D.D. 1997. «Proximate composition and energy density of some North Pacific forage fishes». Comparative Biochemistry and Physiology, 118 (4), 1393-1398.

[12] LlORET J., SHULMAN G. eta LOVE R.M. 2014. Condition and Health Indicators of Exploited Marine Fishes. Wiley-Blackwell, Chichester, UK.

[13] MAZZOCCHI M.G. eta RIBERA D’ALCALÀ M. 1995. «Recurrent patterns in zooplankton structure and succession in a variable coastal environment». ICES Journal of Marrine Science, 52, 679-691.

[14] COMA R., RIBES M., GILI J.M. eta ZABALA M. 2000. «Seasonality in coastal benthic ecosystems». Trends in Ecology and Evolution, 15, 448-453.

[15] ALBO-PUIGSERVER M., MUÑOZ A., NAVARRO J., COLL M., PETHYBRIDGE H., SÁNCHEZ S. eta PALOMERA I. 2017. «Ecological energetics of forage fish from the Mediterranean Sea: Seasonal dynamics and interspecific differences». Deep-Sea Research II, 140, 74-82.

[16] BACHA M. eta AMARA R. 2009. «Spatial, temporal and ontogenetic variation in diet of anchovy (Engraulis encrasicolus) on the Algerian coast (SW Mediterranean)». Estuarine, Coastal and Shelf Science, 85, 257-264.

[17] CUSHING D.H. 1975. Marine ecology and fisheries. Cambridge University Press. Londres, UK.

[18] MOTOS L., URIARTE A. eta VALENCIA V. 1996. «The spawning environment of the Bay of Biscay anchovy (Engraulis encrasicolus L.)». Scientia Marina, 60 (2), 117-140.

[19] ROSSOLL D., BERMÚDEZ R., HAUSS H., SCHULZ K.G., RIEBESELL U., SOMMER U. eta WINDER M. 2012. «Ocean Acidification-Induced 
Food Quality Deterioration Constrains Trophic Transfer». PLoS One, 7 (4), e34737.

[20] FANJUL A., IRIARTE A., VILLATE F., URIARTE I. eta ATKINSON A. 2018. «Zooplankton seasonality across a latitudinal gradient in the Northeast Atlantic Shelves Province». Continental Shelf Research, 160, 49-62.

[21] BARROETA Z., OLIVAR M.P. eta PALOMERA I. 2017. «Energy density of zooplankton and fish larvae in the southern Catalan Sea (NW Mediterranean)». Journal of Sea Research, 124, 1-9.

[22] FANJUL A. VILLATE F., URIARTE I., IRIARTE A., ATKINSONS A. eta COOK K. 2017. «Zooplankton variability at four monitoring sites of the Northeast Atlantic Shelves differing in latitude and trophic status». Journal of Plankton Research, 39 (6), 891-909.

[23] IRIGOIEN X., FERNANDES J.A., GROSJEAN P., DENIS K., ALBAINA A. eta SANTOS M. 2009. «Spring zooplankton distribution in the Bay of Biscay from 1998 to 2006 in relation with anchovy recruitmente». Journal of Plankton Research, 31 (1), 1-17.

[24] KOUTSIKOPOULOS C. eta LE CANN B. 1996. «Physical processes and hydrological structures related to the Bay of Biscay anchovy». Scientia Marina, 60, 9-19.

[25] OSTOJIĆ A.M. 2000. «Effect of eutrophication on changes in the composition of zooplankton in the Grošnica Reservoir (Serbia, Yugoslavia)». Hydrobiologia, 436 (1-3), 171-178.

[26] GUENTHER M. eta VALENTIN J.L. 2008. «Bacterial And Phytoplankton Production In Two Coastal Systems Influenced By Distinct Eutrophication Processes». Oecologia Brasiliensis, 12(01), 172-178.

[27] FONTÚRBE F. MOLINA C. eta RICHARD E. 2006. «Evaluación rápida de la diversidad de fitoplancton en aguas eutróficas del lago Titikaka (Bolivia) y su uso como indicador del grado de contaminación». Ciencia Abierta Internacional, 29, 1-12.

[28] BODE A., CARRERA P., GONZÁlEZ-NUEVO G., NOGUEIRA E., RIVEIRO I. eta SANTOS M.B. 2018. «A trophic index for sardine (Sardina pilchardus) and its relationship to population abundance in the southern Bay of Biscay and adjacent waters of the NE Atlantic». Progress in Oceanography, 166, 139-147.

[29] SEMENOVA A. eta ALEKSANDROV S.V. 2009. «The zooplankton consumption of primary production and an assessment of the waterbody trophic state on the basis of its structural and functional characteristics». Inland Water Biology, 2 (4), 348-354.

[30] BAKUN A., FIELD D.B., REDONDO-RODRIGUEZ A. eta WEEKS S.J. 2010. «Greenhouse gas, upwelling-favorable winds, and the future of coastal ocean upwelling ecosystems». Global Change Biology, 16 (4), 1213-1228.

[31] RAHMSTORF S. 2006. Thermohaline Ocean Circulation. In: Encyclopedia of Quaternary Sciences, Edited by S. A. Elias. Elsevier, Amsterdam. 
[32] DO SOUTO M., SPINELLI M.L., BROWN D.R., PÁJARO M., DIAZ M.V. eta CAPITANIO F.I. 2018. «Benefits of frontal waters for the growth of Engraulis encrasicolus larvae: The influence of food availability». Fisheries Research, 204, 181-188.

[33] PATUREJ E. eta GUTKOWSKA A. 2015. «The effect of salinity levels on the structure of zooplankton communities». Archives of Biological Sciences, 67 (2), 483-492.

[34] KAPLAN I.C., KOEHN L.E., HODGSON E.E., MARSHALL K.N. eta ESSINGTON T.E. 2017. «Modeling food web effecths of low sardine and anchovy abundance in the California Current». Ecological Modelling, 359, $1-24$.

[35] DESSiER A., BUSTAMANTE P., CHOUVELON T., HURET M., PAGANO M., MARQUIS E., ROUSSEAUX F., PIGNON-MUSSAUD C., MORNET F., BRÉRET M. eta DUPUY D. 2018. «The spring mesozooplankton variability and its relationship with hydrobiological structure over year-to-year changes (2003-2013) in the southern Bay of Biscay (Northeast Atlantic)». Progress in Oceanography, 166, 76-87.

[36] MARIN I., NUNES S., SÁNCHEZ-PÉREZ E.D., TXURRUKA E., ANTEQUERA C., SALA M.M., MARRASÉ C. eta PETERS F. 2017. «Coastal Bacterioplnakton Metabolism Is Stimulated Stronger By Anthropegin Aerosols Than Saharan Dust». Frontiers in Microbiology, 8, 2215.

[37] ALHEIT J. 1987. «Egg cannibalism versus egg predation: their significance in anchovies». South African Journal of Marine Science, 5, 467-470.

[38] BUTLER J.L. 1991. «Mortality and recruitment of pacific sardine, Sardinops sagax caerulea, larvae in the California current». Canadian Journal of Fisheries and Aquatic Sciences, 48, 1713-1723.

[39] CHAMBERS R.C., LEGGETT W.C. eta BROWN J.A. 1989. «Egg Size, Female Effects, and the Correlations Between Early Life History Traits of Capelin, Mallotus villosus: An Appraisal at the Individual Levell». Fishery Bulletin - National Oceanic and Atmospheric Administration, 87 (3), 515523.

[40] DIAZ E., TXURRUKA J.M. eta VILLATE F. 2009. «Biochemical composition and somatic growth of pelagic larvae of three fish species from the Bay of Biscay». Marine Ecology Progress Series, 382, 173-183.

[41] HEWITT R.P., THEILACKER G.H. eta LO N.C.H. 1985. «Causes of mortality in young jack mackerel». Marine Ecology Progress Series, 28, 1-10.

[42] IRIGOIEN X. eta DE ROOS A. 2011. «The role of intraguild predation in the population dynamics of small pelagic fish». Marine Biology, 158, 16831690.

[43] MCGURK M.D. 1986. «Natural mortality of marine pelagic fish eggs and larvae: role of spatial patchiness». Marine Ecology Progress Series, 34, 227-242.

[44] TAGGART C.T. eta LEGGETT W.C. 1987a. «Short-term mortality in postemergent larval capelin Mallotus villosus. I. Analysis of multiple in situ estimates». Marine Ecology Progress Series, 41, 205-217. 
[45] VALDES-SZEINFIELD E. 1991. «Cannibalism and intraguild predation in clupeoids». Marine Ecology Progress Series, 79, 17-26.

[46] WARE D.M. eta LAMBERT T.C. 1985. «Early life history of Atlantic mackerel Scomber scombrus) in the southern Gulf of St. Lawrence». Canadian Journal of Fisheries Aquatic Science, 42, 577-592.

[47] BACHILLER E., COTANO U., IBAIBARRIAGA L., SANTOS M. eta IRIGOIEN X. 2015. «Ingraulid predation between small pelagic fish in the Bay of Biscay: impact on anchovy (Engraulis encrasicolus L.) egg mortality». Marine Biology, 162, 1351-1369.

[48] ALBAINA A., IRIGOIEN X., ALDALUR U., COTANO U., SANTOS M., BOYRA G. eta ESTOMBA A. 2015. «A real-time PCR assay to estimate invertebrate and fish predation on anchovy eggs in the Bay of Biscay». Progress in Oceanography, 131, 82-99.

[49] PURCELL J.E., NEMAIE D.A., DORSEY S.E., HOUDE E.D. eta GAMBLE J.C. 1994. «Predation mortality of bay anchovy (Anchoa mitchilli) eggs and larvae due to scyphomedusae and ctenophores in Chesapeake Bay». Marine Ecology Progress Series, 114, 47-58.

[50] HURST T.P. 2007. «Causes and consequences of winter mortality in fishes». Journal of Fish Biology, 71 (2), 315-145.

[51] LAPOLLA A.E. 2001. «Bay anchovy Anchoa mitchilli in Narragansett Bay, Rhode Island. I. Population structure, growth and mortality». Marine Ecology Progress Series, 217, 93-102.

[52] BACHILLER E. eta IRIGOIEN X. 2015. «Trophodynamics and diet overlap of small pelagic fish species in the Bay of Biscay». Marine Ecology Progress Series, 534, 179-198.

[53] NIKOLIOUDAKIS N., ISARI S. eta SOMARIS S. 2014. «Trophodynamics of anchovy in a non-upwelling system: direct comparison with sardine». $M a$ rine Ecology Progress Series, 500, 215-229.

[54] MILLAR J.S. eta HICKLING G.J. 1990. «Fasting endurance and the ecolution of mammalian body size». Functional Ecology, 4, 5-12.

[55] BROSSET P., FROMENTIN J.M., MÉNARD F., PERNET F., BOURDEIX J.H., BIGOT J.L., VAN BEVEREN E., PÉREZ RODA M.A., CHOY S. eta SARAUX C. 2015. «Measurement and analysis of small pelagic fish condition: A suitable method for rapid evaluation in the field». Journal of Experimental Marine Biology and Ecology, 462, 90-97.

[56] KRAMS I.A., RUMVOLT K., SAKS L., KRAMS R., ELFERTS D., VRUBLEVSKA J., RANTALA M.J., KECKO S., CĪRULE D., LUOTO S. eta KRAMA T. 2017. «Reproduction compromises adaptive immunity in a cyprinid fish». Ecological Research, 32, 559-566.

[57] SARAUX C., VAN BEVEREN E., BROSSET P., QUEIROS Q., BOURDEIX J.H., DUTTO G., GASSET E., JAC C., BONHOMMEAU S. eta FROMENTIN J.M. 2019. «Small pelagic fish dynamics: A review of mechanisms in the Gulf of Lions». Deep-Sea Research Part II, 159, 52-61. 
[58] VAN BEVEREN E., KECK N., FROMENTIN J.M., LAURENCE S., BOULET H., LABRUT S., BAUD M., BIGARRÉ L., BROSSET P., BONHOMMEAU S. eta SARAUX C. 2016b. «Can pathogens alter the population dynamics of sardine in the NW Mediterranean?». Marine Biology, 163 (12), 240.

[59] DE LIBERATO C., BOSSU T., SCARAMOZZINO P., NICOLINI G., CEDDIA P., MALLOZZI S., CAVALlERO S. eta D'AMELIO S. 2013. «Presence of anisakid larvae in the European anchovy, Engraulis encrasicolus, fished off the Tyrrhenian coast of central Italy». Journal of Food Protection, 76, 1643-1648.

[60] GUTIERREZ-GALINDO J.F., OSANZ-MUR A.C. eta MORA-VENTURA M.T. 2010. «Occurrence and infection dynamics of anisakid larvae in Scomber scombrus, Trachurus trachurus, Sardina pilchardus, and Engraulis encrasicolus from Tarragona (NE Spain)». Food Control, 21, 1550-1555.

[61] MLADINEO I., SIMAT V., MILETIC J, BECK R. eta POLJAK V. 2012. «Molecular identification and population dynamic of Anisakis pegreffii (Nematoda: Anisakidae Dujardin, 1845) isolated from the European anchovy (Engraulis encrasicolus L.) in the Adriatic Sea». International Journal of Food Microbiology, 157, 224-229.

[62] RELLO F.J., ADROHER F.J., BENITEZ R. eta VALERO A. 2009. «The fishing area as a possible indicator of the infection by anisakids in anchovies (Engraulis encrasicolus) from southwestern Europe». International Journal of Food Microbiology, 129, 277-281.

[63] SERRACCA L., BATTISTINI R., ROSSINI I., CARDUCCI A., VERANI M., PREARO M., TOMEI L., DE MONTIS G. eta ERCOLINI C. 2014. «Food safety considerations in relation to Anisakis pegreffii in anchovies (Engraulis encrasicolus) and sardines (Sardina pilchardus) fished off the Ligurian Coast (Cinque Terre National Park, NW Mediterranean)». International Journal of Food Microbiology, 190, 79-83.

[64] FERRER-MAZA D., LLORET J., MUÑOZ M., FALIEX E., VILA S. eta SASAL P. 2016. «Links between parasitism, energy reserves and fecundity of European anchovy, Engraulis encrasicolus, in the northwestern Mediterranean Sea». Conservation Physiology, 4 (1), cov069.

[65] DIAZ E., TXURRUKA J.M. eta VILLATE F. 2011. «Growth maximization in early sardine larvae: a metabolic approach». Marine Biology, 158, 11351148 .

[66] BIRKELAND C. eta DAYTON P.K. 2005. «The importance in fishery management of leaving the big ones». TRENDS in Ecology and Evolution, 20 (7), 356-358.

[67] DOMÍNGUEZ-PETIT R. eta SABORIDO-REY F. 2010. «New bioenergetic perspective of European hake (Merluccius merluccius L.) reproductive ecology». Fisheries Research, 104, 83-88.

[68] NUNES C., SILVA A., SOARES E. eta GANIAS K. 2011a. «The Use of Hepatic and Somatic Indices and Histological Information to Characterize 
the Reproductive Dynamics of Atlantic Sardine Sardine pilchardus from the Portuguese Coast». Marine and Coastal Fisheries: Dynamics, Management, and Ecosystem Science, 3, 127-144.

[69] NUNES C., SILVA A., MARQUES V. eta GANIAS K. 2011b. «Integrating fish size, condition, and population demography in the estimation of Atlantic sardine annual fecundity». Ciencias Marinas, 37 (4B), 565-584.

[70] BARNECHE D.R., ROBERTSON D.R., WHITE C.R. eta MARSHALL D.J. 2018. «Fish reproductive-energy output increases disproportionately with body size». Science, 360, 642-645.

[71] HERTING G.E. eta WITT A.J. 1967. «The role of physical fitness of forage fishes in relation to their vulnerability to predation by Bowfin (Amia calva)». Transactions of the American Fisheries Society, 96 (4), 427-430.

[72] VAN BEVEREN E., FROMENTIN J.M., BONHOMMEAU S., NIEBLAS A.E., METRAL L., BRISSET B., JUSUP M., BAUER R., BROSSET P. eta SARAUX C. 2017. «Predator-prey interactions in the face of effective management strategies: changes in Mediterranean small pelagics are not due to increased tuna predation». Canadian Journal of Fisheries and Aquatic Sciences, 74 (9), 1422-1430.

[73] DEVINE J.A., WRIGHT P.J., PARDOE H.E. eta HEINO M. 2012. «Comparing rates of contemporary evolution in life-history traits for exploited fish stocks». Canadian Journal of Fisheries and Aquatic Sciences, 69, 11051120 .

[74] AUDZIJONYTE A., KUPARINEN A. eta FULTON E.A. 2013. «How fast is fisheries-induced evolution? Quantitative analysis of modelling and empirical studies». Evolutionary Applications, 6, 585-595.

[75] KUPARINEN A., BOIT A., VALDOVINOS F.S., LASSAUX H., eta MARTINEZ N.D. 2016. «Fishing induced life-history changes degrade and destabilize harvested ecosystems». Scientific Reports, 6, 22245.

[76] MOLLET F.M., DIECKMANN U. eta RIJNSDORP A.D. 2016. «Reconstructing the effects of fishing on life-history evolution in North Sea plaice Pleuronectes platessa». Marine Ecology Progress Series, 542, 195-208.

[77] PATTERSON K. 1992. «Fisheries for small pelagic species: an empirical approach to management targets». Reviews in Fish Biology and Fisheries, 2, 321-338.

[78] BAKUN A. eta PARRISH R.H. 1982. «Turbulence, transport and pelagic fish in the California and Peru current systems». California Cooperative Oceanic Fisheries Investigations Report, 23, 99-112.

[79] PARRISH R.H., BAKUN A., HUSBY D.M. eta NELSON C.S. 1983. «Comparative climatology of selected environmental processes in relation to eastern boundary current pelagic fish reproduction». FAO Fisheries Report, 291 (3), 731-777.

[80] CURY P. eta ROY C. 1989. «Optimal environmental window and pelagic fish recruitment success in upwelling areas». Canadian Journal of Fisheries and Aquatic Sciences, 46, 670-680. 
[81] GURASLAN C., FACH B.A. eta OGUZ T. 2017. «Understanding the Impact of Environmental Variability on Anchovy Overwintering Migration in the Black Sea and its Implications for the Fishing Industry». Frontiers in Marine Science, 4, 275.

[82] BORJA A., URIARTE A., VALENCIA V., MOTOS L. eta URIARTE A. 1996. «Relationships between anchovy (Engraulis encrasicolus) recruitment and the environment of the Bay of Biscay». Scientia Marina, 60 (2): The European Anchovy and its Environment, Eds. PALOMERA I. eta RUBIES P., 179-192.BORJA A, URIARTE A., EGAÑA J., MOTOS L. eta VALENCIA V. 1998. «Relationship between anchovy (Engraulis encrasicolus L.) recruitment and environment in the Bay of Biscay». Fisheries Oceanography, 7 (3-4), 375-380.

[83] IRIGOIEN X., FIKSEN Ø., COTANO U., URIARTE A., ALVAREZ P., ARRIZABALAGA H., BOYRA G., SANTOS M., SAGARMINAGA Y., OTHEGUY P., ETXEBESTE E., ZARAUZ L., ARTETXE I. eta MOTOS L. 2007. «Could Biscay Bay Anchovy recruit through a spatial loophole?». Progress in Oceanography, 74, 132-148.

[84] URIARTE A., SAGARMINAGA Y., SCALABRIN C., VALENCIA V., CERMEÑO P., DE MIGUEL E., GOMEZ-SANCHEZ J.A. eta JIMENEZ M. 2001. «Ecology of anchovy juveniles in the Bay of Biscay 4 months after peak spawning: do they form part of the plankton». ICES CM/W:20.

[85] LASKER R. 1978. «The relation between oceanographic conditions and larval anchovy food in the California current: identification of factors contributing to recruitment failure. Details - Rapports et procès-verbaux des réunions, Conseil Permanent International pour l'Exploration de la Mer, 173, 212-230.

[86] ALLAIN G., PETITGAS P. eta LAZURE P. 1999. «Environmental and stock effects on the recruitment of anchovy in the Bay of Biscay: A multivariate analysis». ICES CM 1999/ Y:22.

[87] KOUTSIKOPOULOS C. eta LE CANN B. 1996. «Physical processes and hydrological structures related to the Bay of Biscay anchovy». Scientia Marina, $60(2), 9-19$.

[88] HARO-GARAY M.J. eta HUATO SOBERANIS L. 2008. «Cambio en el zooplancton dominante del estrecho de Georgia, British Columbia durante 1997». Hidrobiológica, 18 (1), 53-60.

[89] BAKUN A. eta BROAD K. 2003. «Environmental "loopholes" and fish population dynamics: comparative pattern recognition with focus on El Niño effects in the Pacific». Fisheries Oceanography, 12 (4/5), 458-473,

[90] GRAY W. M. 1984. «Atlantic seasonal hurricane frequency. Part I: El Niño and $30 \mathrm{mb}$ quasi-biennial oscillation influences». Monthly Weather Review, 112, 1649-1668.

[91] SARAVANAN R. eta CHANG P. 2000. «Interaction between Tropical Atlantic Variability and El Niño-Southern Oscillation». Journal of Climate, 13 (13), 2177-2194. 
[92] RICHARDSON S.L. 1981. «Spawning biomass and early life of northern anchovy, Engraulis mordax, in the northern subpopulatin off Oregon and Washington». Fishery Bulletin, 78, 855-876.

[93] PALOMERA I. 1989. Primeras fases del desarrollo de la anchoa, (Engraulis encrasicolus) en la Costa Catalana. Ph. D. thesis, Universitat de Barcelona, Barcelona.

[94] LIMA I.D. eta Castello J.P. 1995. «Distribution and abundance of southwest Atlantic anchovy spawners (Engraulis anchoita) in relation to oceanographic processes in the southern Brazilian shelf». Fisheries Oceanography, 4, 1-16.

[95] ANON. 1994. Small Pelagic Fishes and Climate Change Program. Globec Report Series. La Paz, México.

[96] MORALES J. eta LIZANA M. 2014. «Efectos negativos del cambio climático aceleran la extinción de la principal población de la náyade Margaritifera margaritifera L., 1758 en la cuenca del Duero». Munibe (Ciencias Naturales-Natur Zientziak), 62, 25-49.

- Euskalterm: http://www.euskadi.eus/euskalterm/

- Harluxet: http://www1 .euskadi.net/Harluxet/

\section{GLOSARIOA}

Bitelo: garatze-bidean dagoen enbrioia elikagaiz hornitzen duen obuluko materiala.

Bloom: fitoplankton espezie baten populazioaren bat-bateko hazkundea, ur masa osoa betetzen duena.

Espezie pelagiko: ur zutabean bizi den espeziea, ez hondoan ez hondoaren gainean.

Eklosionatu: arrautzatik jaio.

Ekmanen garraio: kontinenteen mendebaldeko itsasertzetako alisioek Coriolisen indarrarekin batera itsasertzarekiko elkarzut urrunduz doan urlaster bat sorrarazten dutenean gertatzen den fenomenoa. Era horretara desplazatzen den urak hutsune bat uzten du, eta hutsune hori hondoko ur hotz eta oso gaziak ordezkatzen du, azpiko urak azaleratuz, alegia.

Erlazio alometriko: ale txikiek handiek baino metabolismo bizkorragoa izatea gramoko.

Errekrutamendu: ale helduen multzora urtero gehitzen diren ale gazte berrien gehitzea.

Eutrofizazio: ur korronte eta bilduetan mantenugai gehiegi aurkitzea, eskuarki kutsaduraren ondorioz. Ekosistema urtarren desoreka ekartzen du.

Fitoplankton: planktona osatzen duen landare mikroskopikoen multzoa. fitoplanktona osatzen duten talde batzuk dira, esaterako, diatomeoak, dinoflagelatuak, tintinidoak, etab. 
Fotoperiodo: argitasun- eta iluntasun-periodo txandakatuetan, argialdiaren luzera erlatiboa. Adibidez, egunaren eta gauaren luzera erlatiboa.

Gantz azido: hidrokarburo-kate batek eta karboxilo talde batek osatutako konposatu organikoa, zenbait lipido-motaren osagai dena. Gantz azidoak aseak izan daitezke (hidrokarburo-katean dauden karbono guztien arteko lotura sinplea denean) edo asegabeak (behintzat bi karbonoren artean dagoen lotura bikoitza denean).

Hidrologia: uraren ezaugarriak eta, bereziki, lur gaineko eta lurpeko uren banaketa eta zirkulazioa aztertzen dituen zientzia.

Hipoxia: oxigeno falta.

Ibai luma: ibaia itsasoratzean sortzen duen ur masa geza, ibaiko partikulak daramatzana.

Katabolismo: produktu organikoen degradazioan gertatzen diren prozesu metabolikoen multzoa. Metabolismoaren bi faseetako bat da.

Kate trofiko (edo elikakate): ekosisteman janari-harremanen arabera antolaturiko organismo-sekuentzia; organismo bakoitza bere hurrengo kate-mailan dagoenak jaten du. Ekosistema bateko elikakateen multzoak elikasarea osatzen du.

Kontinente-ezponda (edo kantil): kontinenteen ertzean, plataforma kontinentalaren eta itsas hondo abisalen artean aurkitzen den zona maldatsua.

NAO eta EA: Ipar Atlantikoari eragiten dioten konexio-ereduak, itsasoko ekosistemetan eta zooplankton komunitateetan aldaketak izan ditzaketenak. NAO Ipar Atlantikoko Oszilazioa (ingelesez: North Atlantic Oscillation, NAO) eta EA Ekialdeko Atlantiar oszilazioa (ingelesez East Atlantic pattern).

Oligotrofiko: ingurune urtar bati buruz mintzatzean, mantenugai mineral urriak dituena.

Plankton: uretako organismo txikiek osatutako multzoa, uretan pasiboki flotatuz bizi dena.

Substantzia humikoa: materia organikoaren parte diren molekula txikien nahaste heterogeneoa.

Termoklina: ur-masetan aurkitu ohi den ur-geruza, ur-masa bitan banatzen duena: gainekoa (epilimniona), beroagoa eta ongi oxigenatua, eta azpikoa (hipolimniona), hotzagoa eta oxigeno gutxiago duena.

Upwelling (azaleratzea): ur-masa batean, azpiko ur hotz eta elikagaietan joriak gainazalera irteten diren lekua.

Ur zutabe estratifikatua: ur zutabean dentsitate desberdineko bi ur masa ondo desberdinduak aurkitzen direnean, bata gainazalean (normalean dentsitate baxuagokoa) eta bestea hondoan (dentsitate handiagokoa).

Zirkulazio antiziklonikoa: antizikloi bati dagokion zirkulazio atmosferiko sistematikoa, hots, ipar-hemisferioan erloju-orratzen eran biratzen dena, eta aurkako noranzkoan hego-hemisferioan.

Zirkulazio termohalino: 1. itsasoko uraren dentsitateak Ozeano Atlantikoaren iparraldean gora egitearen ondorioz sortzen den itsaslaster-sistema. 2. ur- 
Estibalitz Txurruka Alberdi, Ziortza Barroeta Legarreta, Álvaro Fanjul Miranda

masa handi batean azaleko ura hozten denean gertatzen den uraren zirkulazio bertikala, ura nahastea dakarrena.

Zooplankton: planktona osatzen duen animalia mikroskopikoen multzoa. Zooplanktona osatzen duten talde batzuk dira, esaterako, ziklopodoak, apendikularioak, kopepodoak, knidarioak, sifonoforoak, etab. 